\title{
Effect of age at onset on frequency of depression in Parkinson's disease
}

\author{
Vladimir S Kostić, Saša R Filipović, Dušica Lečić, Dragana Momčilović, Dragoslav Sokić, \\ Nadežda Šternić
}

\begin{abstract}
In a consecutive series of 169 outpatients with Parkinson's disease the frequency of depression was compared in two groups: those who developed Parkinson's disease before the age of 50, and those who developed the disease after 50. Major depression was found in $36 \%$ of patients with early onset and in $16 \%$ of patients with late onset Parkinson's disease. This significant difference disappeared when both groups were matched for duration of Parkinson's disease. A stepwise regression analysis in both the early onset and the late onset Parkinson's disease showed a significant correlation only between depression scores and the impairment scores of activities of daily living.
\end{abstract}

(F Neurol Neurosurg Psychiatry 1994;57:1265-1267)

Depression is the most common behavioural problem in Parkinson's disease. ${ }^{12}$ Controversy still exists, however, regarding the influence of the age at onset of Parkinson's disease on the frequency of depression. The widespread clinical impression that depression is more common or severe in Parkinson's disease of earlier onset was not confirmed in studies investigating such a correlation. ${ }^{23}$

We examined a large number (169) of consecutive outpatients with Parkinson's disease for the presence of depression with standardised psychiatric instruments. The frequency of depression was evaluated in two groups of patients-namely, those with early and those with late onset Parkinson's disease, based on an arbitrary age of 50 years.

Institute for

Neurology CCS,

Belgrade, Yugoslavia

V S Kostic

S R Filipović

D Lečić

D Momćilović

D Sokić

N Śternić

Correspondence to: $\mathrm{Dr}$ Vladimir S Kostić, Institute for Neurology CCS, ul Dr Subotića 6, 11000 Belgrade, Yugoslavia.

Received 3 September 1993 and in final revised form 11 April 1994.

Accepted 22 April 1994 The study comprised 169 consecutive patients with the diagnosis of idiopathic Parkinson's disease. For precision, data on the age at onset of Parkinson's disease from clinical records were compared with the same data obtained from the interviews with patients and their family members. The patients were then divided into two groups: those with an age at onset of Parkinson's disease $\leqslant 50$ years formed the early onset group, and patients with an age at onset $>50$ years formed the late onset group. At the time of the study, the stage of Parkinson's disease (Hoehn and Yahr scale) ${ }^{4}$ was determined for each patient, and activities of daily living were measured with the North Western disability scale (NWDS). ${ }^{5}$ Cognitive impairment was assessed by means of the mini-mental state examination.

All subjects were interviewed by a trained rater, blind to the neurological data, using the Schedule of affective disorders and schizophrenia. ${ }^{6}$ The patients received a diagnosis of major or minor depressive disorder by Research diagnostic criteria. ${ }^{7}$ The severity of depression was scored according to the Hamilton depression rating scale. ${ }^{8}$

Statistical analysis was performed on means and SDs by analysis of variance (ANOVA), the $\chi^{2}$ test with Yates' correction or Fisher's exact test in the case of qualitative variables, the Kruskal-Wallis analysis of variance with corresponding post hoc comparisons, and stepwise regression analysis.

\section{Results}

In the early onset group, 25 patients (36\%) had major depression and eight (11\%) had minor depression, whereas in the late onset group, 16 patients (16\%) had major depression and $14(14 \%)$ had minor depression (table 1). The hypothesis of equal frequency of major, minor, or no depression based on the presence of an early $v$ late onset of Parkinson's disease was rejected $\left(\chi^{2}=8 \cdot 77\right.$, $\mathrm{df}=2, \mathrm{p}=0.012$ ). This was the result of a significantly higher frequency of major depression in the early onset compared with the late onset group $\left(\chi^{2}=8 \cdot 74, \mathrm{df}=1, \mathrm{p}=\right.$ 0.003 ; with Yates' correction $=7 \cdot 70, \mathrm{df}=1$, $p=0 \cdot 006)$. No significant between group differences were seen in the frequency of minor depression $\left(\chi^{2}=0.24, \mathrm{df}=1, \mathrm{p}=0.62\right.$; with Yates' correction $=0.07, \mathrm{df}=1, \mathrm{p}=0.80$ ).

These results suggest that patients with an early onset of the disease had a significantly higher frequency of major depression than the patients with late onset Parkinson's disease, but we did not control for the duration of the disease (significantly longer in early onset parkinsonism; $F=14.4 ; \mathrm{df}=1,167 ; \mathrm{p}<$ 0.0002). We therefore selected two subgroups with duration of Parkinson's disease more than two, but less than 10 years: one 


\begin{tabular}{|c|c|c|c|c|c|c|}
\hline & \multicolumn{3}{|c|}{$\begin{array}{l}\text { Depression in early onset Parkinson's disease } \\
(\leqslant 50 y)\end{array}$} & \multicolumn{3}{|c|}{$\begin{array}{l}\text { Depression in late onset Parkinson's disease } \\
(>50 \mathrm{y})\end{array}$} \\
\hline & Major & Minor & None & Major & Minor & None \\
\hline $\begin{array}{l}\text { No of patients } \\
\text { Sex (male/female ratio) } \\
\text { Age (y) }{ }^{\star} \\
\text { Age at onset }(y) \\
\text { Duration of Parkinson's disease }(y) \dagger \\
\text { Duration of levodopa treatment }(y) \\
\text { Levodopa dosage (mg/day) } \\
\text { NWDS } \ddagger \\
\text { Hoehn and Yahr stage } \$ \\
\text { HDRS\| } \\
\text { MMSE }\end{array}$ & $\begin{array}{l}25 \\
16 / 9 \\
50 \cdot 0(8 \cdot 9) \\
43 \cdot 2(7 \cdot 3) \\
6 \cdot 8(4 \cdot 7) \\
4 \cdot 0(3 \cdot 7) \\
408(309) \\
12 \cdot 4(4 \cdot 6) \\
2 \cdot 7(1 \cdot 1) \\
20 \cdot 9(3 \cdot 3) \\
27 \cdot 6(2 \cdot 1)\end{array}$ & $\begin{array}{l}8 \\
7 / 1 \\
52 \cdot 4(8 \cdot 4) \\
44 \cdot 6(4 \cdot 9) \\
7 \cdot 8(5 \cdot 7) \\
5 \cdot 6(4 \cdot 6) \\
515(316) \\
14 \cdot 3(4 \cdot 4) \\
2 \cdot 5(1 \cdot 5) \\
16 \cdot 9(2 \cdot 3) \\
28 \cdot 6(1 \cdot 1)\end{array}$ & $\begin{array}{l}37 \\
28 / 9 \\
47 \cdot 5(7 \cdot 7) \\
42 \cdot 0(7 \cdot 6) \\
5 \cdot 6(5 \cdot 3) \\
2 \cdot 3(2 \cdot 9) \\
326(263) \\
15 \cdot 5(2 \cdot 2) \\
1 \cdot 9(0 \cdot 9) \\
5 \cdot 8(3 \cdot 8) \\
28 \cdot 6(1 \cdot 8)\end{array}$ & $\begin{array}{l}16 \\
9 / 7 \\
63 \cdot 7(5 \cdot 8) \\
59 \cdot 3(5 \cdot 5) \\
4 \cdot 4(2 \cdot 8) \\
2 \cdot 6(3 \cdot 0) \\
410(264) \\
12 \cdot 2(2 \cdot 6) \\
2 \cdot 9(0 \cdot 8) \\
20 \cdot 5(3 \cdot 0) \\
27 \cdot 1(2 \cdot 0)\end{array}$ & $\begin{array}{l}14 \\
7 / 7 \\
62 \cdot 3(7 \cdot 5) \\
59 \cdot 1(5 \cdot 9) \\
3 \cdot 2(3 \cdot 1) \\
2 \cdot 0(2 \cdot 1) \\
366(227) \\
13 \cdot 3(3 \cdot 1) \\
2 \cdot 8(1 \cdot 1) \\
16 \cdot 0(2 \cdot 7) \\
27 \cdot 2(3 \cdot 6)\end{array}$ & $\begin{array}{l}69 \\
39 / 30 \\
62(5 \cdot 7) \\
59 \cdot 0(5 \cdot 1) \\
3 \cdot 5(3 \cdot 2) \\
1.9(2 \cdot 6) \\
400(321) \\
15 \cdot 6(3 \cdot 2) \\
2 \cdot 4(1 \cdot 0) \\
8 \cdot 4(2 \cdot 8) \\
27 \cdot 6(2 \cdot 3)\end{array}$ \\
\hline
\end{tabular}

Values are means (SD). ${ }^{\star}$ Early $v$ late onset, $\mathrm{p}<0.00001$. †Early $v$ late onset, $\mathrm{p}<0.0002$. ¥Major depression $v$ non-depressed in early onset, $\mathrm{p}<0.05$. SMajor depression $v$ non-depressed in both groups, $\mathrm{p}<0.05$. $\|$ Highly significant psychiatric diagnosis
effect, $\mathrm{p}<\cdot 00001$ (ANOVA). NWDS = North Western disability scale; HDRS $=$ Hamilton depression rating scale; MMSE mini-mental state examination.

with early onset Parkinson's disease $(n=39)$, and the second with late onset Parkinson's disease $(n=47)$, with no difference in the duration of the disease (6.0 (SD 0.4$)$ and $5 \cdot 6(0 \cdot 3)$ years respectively; (table 2 ). In this subset of patients, major depression was diagnosed in 17 patients with early onset Parkinson's disease $(43.6 \%)$ and minor depression in four $(10.3 \%)$, whereas in the late onset group 11 patients $(23.4 \%)$ had major and six $(12.8 \%)$ minor depression. With this approach the observed difference in the frequency of major depression based on the age at the beginning of Parkinson's disease was not substantiated $\left(\chi^{2}=3.98, \mathrm{df}=2\right.$, $\mathrm{p}=0 \cdot 14)$. When psychiatric types were analysed separately, there was also no significant difference in frequency of either major depression ( $\chi^{2}$ with Yates' correction $=3.09$, $\mathrm{df}=1, \mathrm{p}=0.08 ;$ Fisher's exact test (two tailed) $p=0.065)$ or minor depression $\left(\chi^{2}\right.$ with Yates' correction $=0.0006, \mathrm{df}=1, \mathrm{p}=$ 0.98; Fisher's exact test (two tailed) $\mathrm{p}=$ $1 \cdot 00)$

It can be argued that these two subgroups were not equal regarding the impairment of activities of daily living (they had different NWDS scores). To control for the possible effects of unequal NWDS scores of the two subgroups on Hamilton depression rating scores, a one way ANOVA (early $v$ late onset patients) with analysis of covariance (NWDS as covariate) for Hamilton depression rating scale scores was performed. When linear effects of NWDS scores $(F=5 \cdot 3, \mathrm{df}=1,83$, $\mathrm{p}=0.024)$ were removed, the ANOVA still

Table 2 Clinical characteristics of two selected groups of patients with early onset and late onset Parkinson's disease, who were matched according to the duration of the disease

\begin{tabular}{|c|c|c|c|c|}
\hline & $\begin{array}{l}\text { Patients with } \\
\text { Parkinson's disease } \\
\text { onset } \leqslant 50 \text { y }\end{array}$ & $\begin{array}{l}\text { Patients with } \\
\text { Parkinson's disease } \\
\text { onset }>50 \text { y }\end{array}$ & F Value & p Value \\
\hline $\begin{array}{l}\text { Number of patients } \\
\text { Age (y) } \\
\text { Duration of levodopa }\end{array}$ & $\begin{array}{l}39 \\
49 \cdot 1(7 \cdot 3)\end{array}$ & $\begin{array}{l}47 \\
64 \cdot 7(5 \cdot 5)\end{array}$ & $\overline{120} \cdot 8$ & $\overline{<0} .00001$ \\
\hline $\begin{array}{l}\text { treatment (y) } \\
\text { Levodopa dosage (mg/day) } \\
\text { Hoehn and Yahr stage } \\
\text { NWDS } \\
\text { HDRS } \\
\text { MMSE }\end{array}$ & $\begin{array}{r}3 \cdot 0(2 \cdot 4) \\
406(249) \\
2 \cdot 3(1 \cdot 2) \\
14 \cdot 3(8 \cdot 9) \\
13 \cdot 8(7 \cdot 9) \\
28 \cdot 3(1 \cdot 8)\end{array}$ & $\begin{array}{r}3 \cdot 4(2 \cdot 7) \\
508(281) \\
2 \cdot 9(0 \cdot 7) \\
9 \cdot 8(6 \cdot 8) \\
12 \cdot 1(5 \cdot 5) \\
26 \cdot 9(2 \cdot 7)\end{array}$ & $\begin{array}{l}0 \cdot 37 \\
2 \cdot 99 \\
6 \cdot 33 \\
5 \cdot 86 \\
1 \cdot 21 \\
8 \cdot 03\end{array}$ & $\begin{array}{l}0.55 \\
0.09 \\
0.012^{\star} \\
0.018 \\
0 \cdot 27 \\
0.006\end{array}$ \\
\hline
\end{tabular}

Values are means (SD); NWDS = North Western disability scale; HDRS = Hamilton depression scale; MMSE = mini-mental state examination.

$\star$ Estimation by Kruskal-Wallis analysis of variance. showed no significant group effect $(F=3 \cdot 2$, $\mathrm{df}=1,83, \mathrm{p}=0.078$ ) on the scores.

A stepwise regression analysis was carried out to establish significant correlates of depression in the early and late onset groups. Hamilton depression rating scale scores were considered as the dependent variable, and age, duration of the disease, levodopa dosage, NWDS, and mini-mental state examination scores as the independent variables. Within both groups, only NWDS scores accounted for a significant part of the variance (early onset group: $F=15.5 ; \mathrm{df}=1,68 ; \mathrm{p}=$ $0 \cdot 0002$; late onset group: $F=5 \cdot 2 ; \mathrm{df}=1,97$; $\mathrm{p}=0.025$ ).

\section{Discussion}

The aim of the study was to determine the relation between the age at onset of Parkinson's disease and the frequency of depression in these patients. Most studies have found no relation between depression and the patients' age at onset of Parkinson's disease, ${ }^{29}$ but Mayeux et al reported that patients with Parkinson's disease associated with depression were generally younger than non-depressed patients. In a consecutive series of patients with early or late onset Parkinson's disease (based on an arbitrary age of 55 years), Starkstein $e t a l^{10}$ reported that the early onset group showed a significantly higher frequency of depression than the late onset group. We also found that patients with early onset Parkinson's disease showed a significantly higher frequency of depression (36\% with major depression compared with $16 \%$ in the late onset group). Contrary to them, ${ }^{10}$ however, after controlling for the duration of the disease (table 2) this significant difference disappeared, and it is suggested that the noted differences in the frequency of depression probably resulted from a different duration of Parkinson's disease in the early onset compared with the late onset group.

In conclusion, this study has not confirmed a higher incidence of depression in patients with early onset Parkinson's disease compared with patients with late onset Parkinson's disease. Also, the results suggest that depression in either early or late onset Parkinson's disease may be related to the 
impairment of activities of daily living, implicating a similar aetiology of depression in both groups.

1 Mayeux R, Stern Y, Rosen J, et al. Depression, intellectual impairment, and Parkinson's disease. Neurology impairment, and

2 Gotham AM, Brown RG, Marsden CD. Depression in Parkinson's disease: a quantitative and qualitative analysis. F Neurol Neurosurg Psychiatry 1989;49:381-9.

3 Huber SJ, Paulson GW, Shuttleworth EC. Depression in Parkinson's disease. Neuropsychiatry, Neuropsychology, and Behavioral Neurology 1988;1:47-51.

4 Hoehn MM, Yahr MD. Parkinsonism: onset, progression and mortality. Neurology 1967;17:427-42.

5 Canter GJ, de La Torre R, Mier M. A method for evaluating disability in patients with Parkinson's disease. $\mathcal{F}$ Nerv Ment Dis 1961;133:143-7.

6 Spitzer RL, Endicott J. Schedule for affective disorders and schizophrenia (SADS). New York: New York State Psychiatric Institute-Biometric Research, 1979.

7 Spitzer RL, Endicott J, Robins E. Research Diagnostic Criteria: rationale and reliability. Arch Gen Psychiatry 1978;35:773-82.

8 Hamilton M. A rating scale for depression. $f$ Neurol Neurosurg Psychiatry 1960;23:56-62.

9 Gibb WRG, Lees AJ. A comparison of clinical and pathological features of young- and old-onset Parkinson's disease. Neurology 1988;38:1402-6.

10 Starkstein SE, Berthier ML, Bolduc PL, et al. Depression in patients with early versus late onset of Parkinson's disease. Neurology 1989;39:1441-5. 